\title{
Prevalence of Aflatoxins in Smoked-Dried and Fresh Fish in Zambia
}

\author{
Indra Sen Singh ${ }^{1^{*}}$, Elasto Nsokolo ${ }^{2}$ \\ ${ }^{1}$ Chemistry Department, School of Mathematics and Natural Sciences, The Copperbelt University, Kitwe, Zambia \\ ${ }^{2}$ National Institute for Scientific and Industrial Research, Lusaka, Zambia \\ Email: *indra@cbu.ac.zm,indra@cbu.ac.zm
}

How to cite this paper: Singh, I.S. and Nsokolo, E. (2020) Prevalence of Aflatoxins in Smoked-Dried and Fresh Fish in Zambia. Journal of Environmental Protection, 11, 13-21.

https://doi.org/10.4236/jep.2020.111002

Received: November 17, 2019

Accepted: January 12, 2020

Published: January 15, 2020

Copyright $\odot 2020$ by author(s) and Scientific Research Publishing Inc. This work is licensed under the Creative Commons Attribution International License (CC BY 4.0).

http://creativecommons.org/licenses/by/4.0/

(c) (i) Open Access

\begin{abstract}
The food contamination is a critical public health concern at the global level. The aflatoxins are considerable food contaminants and health menace to a sizable world population. Aflatoxins originate from fungi as their toxic secondary metabolites. This study aimed to probe the contamination level of aflatoxins in smoked-dried fish and the extent of the threat it might pose on human health. The study considered five of the regularly consumed species of smoked-dried fish. The study also considered two species of fresh fish. The investigation was carried out using VICAM Series-4EX Fluorometer. The Buka fish sample had the lowest concentration of $1.3 \mathrm{ppb}$ for total aflatoxins, and Bream fish was analyzed to have the highest as $3.84 \mathrm{ppb}$. As such, the total aflatoxin concentration in this study was found to be between 1.3 and 3.84 ppb. These concentrations can be considered to be a matter of concern. Prolonged intake of the aflatoxins in this range may result in a health hazard to humans. As expected, there was no trace of aflatoxins detected in fresh fish samples.
\end{abstract}

\section{Keywords}

Aflatoxins, Mycotoxins, Fluorometer

\section{Introduction}

The mycotoxins contamination of food merits serious consideration because of their adverse effect on human or animal health. These are quite stable molecules, and once they sneak in the foodstuff, it is difficult to remove [1]. The factors which affect the susceptibility of foodstuff to mycotoxin contamination include climatic conditions, storage standards, and harvesting mechanism [2]. The studies have established that there are interdependent physical, chemical, and bio- 
logical factors that influence the production of mycotoxins [3]. There has been an extensive study on the devastating effects of mycotoxins on human or animal health [4] [5].

The mould fungi are known to generate aflatoxins, which are complex foodstuff contaminants. There are more than one hundred mycotoxins, which have already been identified. However, six significant aflatoxins merit special mention. These are $B_{1}, B_{2}, G_{1}, G_{2}, M_{1}$, and $M_{2}$ [3]. The aflatoxin M1 and M2 are hydroxylated forms of AFB1 and AFB2 present in milk [6] [7]. The production of several aflatoxins from different moulds has been reported [8]. The species producing the majority of these mycotoxins belong to three fungi genera, namely Aspergillus, Penicillium, and Fusarium [9] [10]. The metabolism of diverse fungi species related to the Aspergillus genus with A. flavus and A. parasiticus strains leads to the formation of aflatoxins [11]. The aflatoxins can be secreted as exotoxins or produced in fungi's spores and mycelium [12].

Mycotoxins are known to trigger a wide range of health problems concerning vital organs [13] [14]. They may have a swift effect, or their long term exposure at relatively low concentration results in chronic problems [15]. Several occurrences of jaundice have been reported from India, Kenya, and Malaysia [16] [17]. Amongst the aflatoxin, $\mathrm{AFB}_{1}$, and $\mathrm{AFB}_{2}$ are considered to be the most toxic and dangerous aflatoxins [10].

Aflatoxins interfere with enzymes and substrates, affecting the critical processes leading to protein synthesis [18]. According to International Agency for Research on Cancer (IARC) [19] and Bennet J. W [11], both aflatoxin $B_{1}$ and $\mathrm{B}_{2}$ are carcinogenic and have been placed in Group 1 of cancer-producing substances [11] [19]. Uptake of sufficient quantities can be highly carcinogenic and acutely toxic or fatal [20] to both humans and livestock. The worst affected organ by aflatoxins is the liver [21]. The earlier studies report that continued consumption of aflatoxin-contaminated foodstuff can lead to liver cancer [21]. It has also been reported that the aflatoxin-contaminated feeds enable metabolic biotransformation of AFB1 in aflatoxin M1 [22]. The aflatoxin M1 and M2 are possibly carcinogenic for humans and have been included in IARC Group 2A of cancer-producing substances [9] [19].

Fish happens to be one of the leading sources of protein in Zambia. Moreover, fish trade also affords a significant source of earnings to many Zambians. Further, a good number of people in Zambia rely on fisheries for their livelihood. Traditional methods are quite famous for fish processing, preservation, and storage in Zambia. Interestingly, a large volume of fish uses traditional methods for processing and preservation.

Some of the most notable traditional methods used in fish processing and preservation include smoke-drying and fermenting. However, smoke-drying is probably the most popular method, and therefore a large volume of the fish is consumed in smoke-dried form. In the rural areas where there are no refrigeration facilities, the smoke-dried fish happens to be the best option as the source of protein. The preference for the smoke-drying method lies in the fact that it is 
low-cost and easy to carry out.

There are some earlier studies reported on the concentration of aflatoxins in dried fish [23] [24] [25]. The impact of aflatoxin-contaminated fish feed has also been studied. According to this study, the fish fed with contaminated feeds can acquire mycotoxins [26].

The earlier study in this area is scarce and insufficient. There is a dearth of information regarding aflatoxin contamination into most of the commonly consumed fish species in Zambia. Moreover, aflatoxins are an acute health hazard. Further, smoke-dried fish is consumed by a significant population in Zambia. Therefore, it would be exciting and significant to quantify aflatoxin concentration in this foodstuff. As such, this study aimed to appraise the prevalence of aflatoxin contamination in commonly consumed fish in Zamia and to highlight the risk posed to the people. This study also considered fresh fish samples to explore aflatoxin contamination, if any, through unknown aflatoxin-contaminated feeds.

\section{Materials and Methods}

\subsection{Sample Collection}

The samples for five types of smoke-dried fish were collected from three provinces of Zambia. The markets selected for sample collection include Chibombo-fish Market (CMO) in Central Province, Chisamba-fish Market (CSM) in Central Province, and Lusaka-Soweto Market (LSK) in Lusaka province of Zambia. Five species of dried fish were sampled randomly at each market. The species considered include bream (Pharyngo chromis acuticeps), Buka (Lates stappersii), Mintesa (M. macrolepidotus), Catfish (Clarias gariepinus), and Makobo (Serranochromis). The sample collections for fresh fish were carried out from superstores. The sample collection for this category was carried out from Copperbelt province (Mukuba Mall), Central Province (Kabwe Mall), and Lusaka Province (Manda Hill Mall).

\subsection{Sample Preparation}

The fish tissue samples were cut using a clean knife and placed into a blender. The sample was then ground at high speed. It was subsequently kept at $-25^{\circ} \mathrm{C}$. The sample was then brought to room temperature and extracted using the VICAM method as stipulated below.

\subsection{Equipment Calibration}

The analysis of fish samples used VICAM Series-4EX Fluorometer for the determination of the aflatoxins concentrations. The concentrations were obtained in the ppb unit. The standard calibration mode for Afla 50 for peanut was followed to calibrate the fluorometer. The calibration check of the system was carried out, and the percent recovery of this method was calculated to be $103.8 \%$ $(5.4 / 5.2) \times 100 \%$. After calibration, each sample was tested for total aflatoxin concentration. 


\subsection{Sample Extraction and Analysis}

\subsubsection{Smoked Dried Fish}

A $50.0 \mathrm{~g}$ of each ground sample was weighed and subsequently transferred to a high-speed stainless steel blender. A $5.0 \mathrm{~g}$ of sodium chloride $(\mathrm{NaCl})$ salt was weighed and dissolved in $100 \mathrm{~mL}$ of a methanol-water mixture $(80: 20, \mathrm{v} / \mathrm{v})$. This solution was also transferred to the jar containing the ground fish sample. The blender was covered, and the sample mixture in the blender was further blended at high speed for one minute. Further, the cover was removed from the jar. The extract was poured into a fluted filter paper, which was fitted with a funnel in a clean vessel. A pipette measured $10 \mathrm{~mL}$ of the filtered extract, which was poured into a clean vessel. The extract was diluted with $40 \mathrm{~mL}$ of wash buffer containing $0.1 \%$ tween PBS. The diluted extract was then filtered using a $0.1 \mu \mathrm{m}$ filter paper.

Further, $10 \mathrm{~mL}$ of the filtered dilute extract was allowed to pass entirely through an AflaTest immuno-affinity column (IAC) (VICAM, Watertown, MA) at a flow rate of $1-2$ drops per second until air came through the column. Further, $10 \mathrm{~mL}$ of deionized water was passed through the column at a rate of about 2 drops per second. This step was repeated by passing $10 \mathrm{~mL}$ of deionized water through the column at a rate of 2 drops per second until air came through the column. All the liquids were removed from the column by applying downward pressure using a pump through the syringe. The aflatoxin was eluted from the affinity column by passing $1.0 \mathrm{~mL}$ of HPLC grade methanol through the column at a rate of $1-2$ drops per second and collected all the sample eluate $(1.0 \mathrm{~mL})$ in glass cuvette. A $1.0 \mathrm{~mL}$ of Afla Test Developer was added to the cuvette and then vortexed to mix thoroughly. The cuvette was covered with aluminium foil after adding the developer to avoid exposure to the light. After 60 seconds, filtration was carried out using nylon filters into the new cuvette. The cuvette was placed in the calibrated fluorometer. The aflatoxin concentration was noted after 60 seconds.

\subsubsection{Fresh Fish}

A $70.0 \mathrm{~g}$ of each sample was weighed. The higher sample weight considered in this case was prompted due to relatively higher water content in the fresh fish samples. It was then dried at $105^{\circ} \mathrm{C}$. After drying, the sample was weighed to be $37.7 \mathrm{~g}$. A similar extraction and analytical procedure was followed in this case, as described earlier for smoked dried fish samples above.

\section{Results}

\subsection{Concentrations of Aflatoxins in Smoked Dried Fish}

The total aflatoxin concentration, as obtained in this study, lies in the range from $1.3 \mathrm{ppb}$ to $2.84 \mathrm{ppb}$. The Buka (CSM) showed the lowest aflatoxin concentration of $1.3 \mathrm{ppb}$, and Bream (LSK) had the highest aflatoxin concentration of $3.84 \mathrm{ppb}$.

The concentrations obtained for all the fish samples are stipulated in Table 1 below. The concentrations are expressed in part per billion (ppb). 
Table 1. Concentration of aflatoxins in smoked dried fish.

\begin{tabular}{cc}
\hline Sample name & Sample Concentration (ppb) \\
\hline Buka LSK & 1.96 \\
Buka CSM & 1.30 \\
Buka CMO & 1.80 \\
Bream LSK & 3.84 \\
Bream CSM & 3.78 \\
Bream CMO & 3.83 \\
Mintesa LSK & 2.60 \\
Mintesa CSM & 2.60 \\
Mintesa CMO & 2.60 \\
Catfish LSK & 3.40 \\
Catfish CSM & 3.40 \\
Catfish CMO & 3.30 \\
Makobo LSK & 1.60 \\
Makobo CSM & 1.60 \\
Makobo CMO & 1.50 \\
\hline &
\end{tabular}

The results for smoke-dried fish samples have also been depicted in Figure 1 below.

\subsection{Concentrations of Aflatoxins in Fresh Fish}

There has been no trace of aflatoxins observed in all the six samples of the fresh fish.

\section{Discussion}

There are many regulatory frameworks for aflatoxin concentrations. These guidelines are variable with geographical divisions, such as Europe, Africa, Asia, USA, Canada [27] [28]. Because of the broader consumption of dried fish in Zambia, this study focused on quantifying aflatoxin presence and the health hazard it might pose. Moreover, no comprehensive study on smoke-dried fish seems to have been carried out in Zambia. Therefore, it was relevant to carry out this study.

Results obtained from this study show a considerable occurrence of aflatoxins in the dried fish sold in Chisamba, Chibombo, and Soweto markets in Zambia. The aflatoxin levels were found to range from $1.3 \mathrm{ppb}$ to $3.84 \mathrm{ppb}$. The bream contained the uppermost value of $3.84 \mathrm{ppb}$ of aflatoxins. The concentration levels are a matter of concern. However, they do not exceed the WHO limit. Although the concentration levels are below the permissible limit, the continued exposure can have a severe effect on human health. 


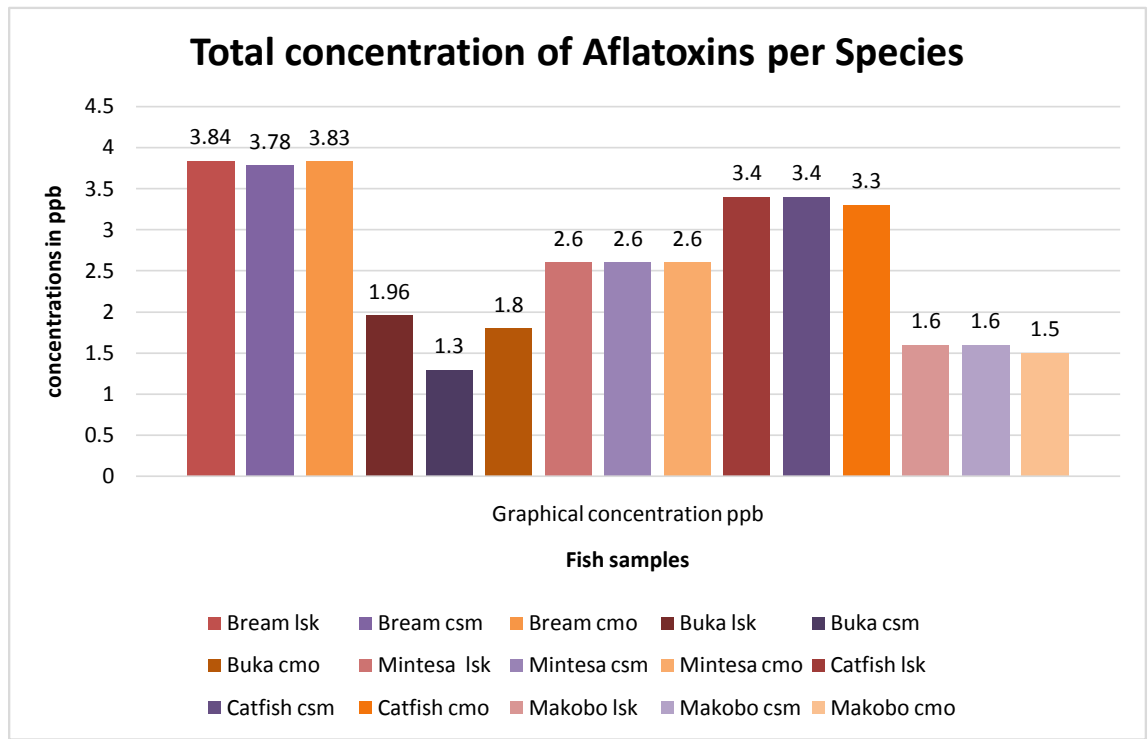

Figure 1. Total concentrations of aflatoxins in fish samples. LSK = Lusaka, CSM $=$ Chisamba, $\mathrm{CMO}=$ Chibombo.

The results obtained in this study are not very far from the one produced by a previous study [23]. Another study [29] reported much lower aflatoxin concentrations from $0.030 \mathrm{ppb}$ to $1.150 \mathrm{ppb}$. The relatively higher amount of aflatoxins in fish samples from Zambia may be attributed to the specific environmental conditions. A study [30] shows that AFs producing fungi grow drastically in moist conditions. Therefore, Zambia, having almost six months of the humid and moist rainy season, is exceptionally favorable for thriving fungi.

A relatively higher concentration in breams may be attributed to the fact that it is relatively expensive. Hence, it has a longer shelf life to favor fungi growth. Often, retailers display the smoked-dried fish samples in trays or heaps, and this favors fungal attack and production of toxins [23].

The purpose of studying fresh fish was to confirm if any trace of aflatoxins were present due to unknown feed factors. However, as per this study, Aflatoxins were not detected in fresh fish. Nevertheless, this study may not assert the absolute absence of aflatoxins conclusively because the method used involved heating at higher temperatures. The studies have established that aflatoxin concentrations drop drastically with temperatures [31] [32]. An alternative method merits to be developed before proclaiming fresh fish absolutely aflatoxin free.

\section{Conclusions}

The concentrations of the aflatoxins in all the fish samples in this study were relatively high but did not exceed WHO limits. However, the amount of aflatoxins found in this study can be a serious health hazard if consumed for an extended period.

The findings are not drastically variant to previous studies. The relatively higher concentration can be attributed to the prolonged wet and humid Zam- 
bian rainy season. As AFs producing fungi thrive in moist conditions, a reliable monitoring system to ascertain the contamination level seems to be a necessity to protect people from the harmful effects of aflatoxins. Fresh fish did not show any concentration of aflatoxins.

The findings of this study indicate that prolonged consumption of smoked dried fish may have a severe health hazard to humans in this country. Further study to include many other fish types merits immediate attention. This study may attract further study to explore better methods of storage and display to reduce and control aflatoxin contamination. There is also a need to investigate the extent of health damage caused by aflatoxins in the Zambian perspective.

\section{Acknowledgements}

Authors gratefully acknowledge the financial and logistical support provided by the Copperbelt University. The useful discussions with the director of NISIR, Dr. H. Njapau, are also gratefully acknowledged.

\section{Conflicts of Interest}

The authors declare no conflicts of interest regarding the publication of this paper.

\section{References}

[1] Bezerra da Rocha, M.E., da Chagas Oliveira Freire, F., Feitosa Maia, F.E., FlorindoGuedes, M.I. and Rondina, D. (2014) Mycotoxins and Their Effects on Human and Animal Health. Food Control, 36, 159-165. https://doi.org/10.1016/j.foodcont.2013.08.021

[2] Tassaneeyakul, W., Razzazi-Fazeli, E., Porasuphatana, S. and Bohm, J. (2004) Contamination of Aflatoxins in Herbal Medicinal Products in Thailand. Mycopathologia, 158, 239-244. https://doi.org/10.1023/B:MYCO.0000041892.26907.b4

[3] D’Mello, J.P.F. and Macdonald, A.M.C. (1997) Mycotoxins. Animal Feed Science and Technology, 69, 155-166. https://doi.org/10.1016/S0377-8401(97)81630-6

[4] Yaling, W., Tongjie, C., Guojhong, L., Chunsan, Q., Huiyong, D., Meiling, Y., Bert-Andree, Z. and Gerd, S. (2008) Simultaneous Detection of Airborne Aflatoxin, Ochratoxin, and Zearalenone in Poultry House by Immunoaffinity Column and High Performance Liquid Chromatography. Environmental Research, 107, 139-144. https://doi.org/10.1016/j.envres.2008.01.008

[5] Averkieva, O. (2008) Mycotoxins in Grains Harvested in 2008: Wheat. Kemin Industries, Inc., Des Moines, IA.

[6] Giray, B., Girgin, G., Engin, A.B., Aydın, S. and Sahin, G. (2007) Aflatoxin Levels in Wheat Samples Consumed in Some Regions of Turkey. Food Control, 18, 23-29. https://doi.org/10.1016/j.foodcont.2005.08.002

[7] Hussain, I. and Anwar, J. (2008) A Study on Contamination of Aflatoxin M1 in Raw Milk in the Punjab Province of Pakistan. Food Control, 19, 393-395. https://doi.org/10.1016/j.foodcont.2007.04.019

[8] Jard, G., Liboz, T., Mathieu, F., Guyonvarc'h, A. and Librihi, A. (2011) Review of Mycotoxin Reduction in Food and Feed: From Prevention in the Field to Detoxification by Adsorption or Transformation. Food Additives and Contaminants: Part 
$A, 28,1590-1609$. https://doi.org/10.1080/19440049.2011.595377

[9] Van Egmond, H.P. (2013) Mycotoxins: Risks, Regulations and European Cooperation. Zbornik Matice Srpske Za Prirodne Nauke, 125, 7-20. https://doi.org/10.2298/ZMSPN1325007V

[10] Cao, H., Huang, H., Xu, W., Chen, D., Yu, J., Li, J. and Li, L. (2011) Fecal Metabolome Profiling of Liver Cirrhosis and Hepatocellular Carcinoma Patients by Ultra Performance Liquid Chromatography-Mass Spectrometry. Analytica Chimica Acta, 691, 68-75. https://doi.org/10.1016/j.aca.2011.02.038

[11] Bennet, J.W. and Klich, M. (2003) Mycotoxins. Clinical Microbiology Reviews, 16, 497-516. https://doi.org/10.1128/CMR.16.3.497-516.2003

[12] Hanssen, E. and Jung, M. (1973) Control of Aflatoxins in the Food Industry. Pure and Applied Chemistry, 35, 239-250. https://doi.org/10.1351/pac197335030239

[13] Bucci, T.J., Howard, P.C., Tolleson, W.H., Laborde, J.B. and Hansen, D.K. (1998) Renal Effects of Fumonisin Mycotoxins in Animals. Toxicologic Pathology, 26, 160-164. https://doi.org/10.1177/019262339802600119

[14] Petzinger, E. and Ziegler, K. (2000) Ochratoxin from a Toxicological Perspective. Journal of Veterinary Pharmacology and Therapeutics, 23, 91-98. https://doi.org/10.1046/j.1365-2885.2000.00244.x

[15] James, B. (2005) Public Awareness of Aflatoxin and Food Quality Control in Benin. International Institute of Tropical Agriculture.

[16] Shephard, G.S. (2004) Mycotoxins Worldwide: Current Issues in Africa. In: Barug, D., Van Egmond, H., Lopez-Garcia, R., Van Ossenbruggen, T. and Visconti, A., Eds., Meeting the Mycotoxin Menace, Wageningen Academic, Wageningen, 81-88.

[17] Lewis, L., Onsongo, M., Njapau, H., Schurz-Rogers, H., Luber, G., Kieszak, S., Nyamongo, J., Backer, L., Dahiye, A.M., Misore, A., Decoct, K. and Rubin, C. (2005) Aflatoxin Contamination of Commercial Maize Products during an Outbreak of Acute Aflatoxicosis in Eastern and Central Kenya. Environmental Health Perspectives, 113, 1763-1767. https://doi.org/10.1289/ehp.7998

[18] Clifford, J.I. and Rees, K.R. (1967) The Interaction of Afiatoxins with Purines and Purine Nucleosides. Biochemical Journal, 103, 467-471. https://doi.org/10.1042/bj1030467

[19] Vidal, A., Mengelers, M., Yang, S., De Saeger, S. and De Boevre, M. (2018) Mycotoxin Biomarkers of Exposure: A Comprehensive Review. Comprehensive Reviews in Food Science and Food Safety, 17, 1127-1155. https://doi.org/10.1111/1541-4337.12367

[20] Shephard, G.S. (2008) Impact of Mycotoxins on Human Health in Developing Countries. Food Additives \& Contaminants. Part A, 25, 146-151. https://doi.org/10.1080/02652030701567442

[21] Neal, G.E. (1995) Genetic Implications in the Metabolism and Toxicity of Mycotoxins. Toxicology Letters, 82-83, 861-867. https://doi.org/10.1016/0378-4274(95)03600-8

[22] Van Egmond, H.P. (1989) Aflatoxin $M_{1}$ : Occurrence, Toxicity, Regulation. In: Van Edmond, H.P., Ed., Mycotoxins in Dairy Products, Elsevier Applied Science, London, 11-55.

[23] Bukola, C. and Adebayo, T. (2008) Mycofloral of Smoke-Dried Fishes Sold in Uyo, Eastern Nigeria. World Journal of Agricultural Sciences, 4, 346-350.

[24] Fredrick, S.J., Immaculate, J.K. and Patterson, E.J.K. (2015) Aflatoxins Investigation on Dried Fishes of Tuticorin, South East Coast of India. Journal of Foodborne and Zoonotic Diseases, 3, 49-62. 
[25] Paul, W.K., Juliet, A., Bandyopadhyay, R. and Peter, J.C. (2018) Aflatoxin Contamination of Dried Insects and Fish in Zambia. Journal of Food Protection, 81, 1508-1518. https://doi.org/10.4315/0362-028X.JFP-17-527

[26] Bruce Manning, B. (2010) Southern Regional Aquaculture Center Publication No. 5002. Mycotoxins in Aquaculture Feed.

[27] Van Egmond, H.P., Schothorst, R.C. and Jonker, M.A. (2007) Regulations Relating to Mycotoxins in Food: Perspectives in a Global and European Context. Analytical and Bioanalytical Chemistry, 389,147-157. https://doi.org/10.1007/s00216-007-1317-9

[28] FAO (2004) Worldwide Regulations for Mycotoxins in Food and Feed in 2003. Food and Agriculture Organization of the United Nations, Food and Nutrition Paper, No. 81, Rome.

[29] Akinyemi, A.A., Adejola, A.Q., Obasa, S.O. and Ezeri, G.N.O. (2011) Aflatoxins in Smoked-Dried Fish Sold in Abeokuta, Ogun State, South-West Nigeria. Proceedings of the Environmental Management Conference, Federal University of Agriculture, Abeokuta, Nigeria.

[30] Hell, K., Fandohan, P., Bandyopadhyay, R., Cardwell, K. and Kiewnick, S. (2008) Pre- and Post-Harvest Management of Aflatoxin in Maize in Mycotoxins: Detection Methods, Management, Public Health and Agricultural Trade. CABI Publishing, Wallingford, UK, 210-219. https://doi.org/10.1079/9781845930820.0219

[31] Yazdanpanah, H., Mohammadi, T., Abouhossain, G. and Cheraghali, A.M. (2005) Effect of Roasting on Degradation of Aflatoxins in Contaminated Pistachio Nuts. Food and Chemical Toxicology, 43, 1135-1139. https://doi.org/10.1016/j.fct.2005.03.004

[32] Elias-Orozco, R., Castellanos-Nava, A., Gaytán-Martínez, M., Figueroa-Cárdenas, J.D. and Loarca-Piña, G. (2002) Comparison of Nixtamalization and Extrusion Processes for a Reduction in Aflatoxin Content. Food Additives \& Contaminants, 19, 878-885. https://doi.org/10.1080/02652030210145054 